\title{
O Processo do Rei: a história no palco do cinema
}

\author{
Mirian Tavares
}

O que fica da história é o que dela se conta (João Mário Grilo).

o falar sobre cinema e encenação, Jacques Aumont conta-nos um episódio que marcou a televisão, e a política francesa, nos anos 80 . Valéry Giscard d'Estaing acabara de ser derrotado na sua tentativa de reeleição como presidente da República e decidiu despedir-se do povo francês pela televisão. $\mathrm{O}$ discurso começou, como todos os discursos transmitidos pela televisão, com o ex-presidente enquadrado em primeiro plano, a falar pausadamente, olhando para a câmara e, de vez em quando, baixando os olhos para ver seus papéis. De repente o enquadramento é alterado, a câmara vai afastando-se e vemos o cenário que o circundava. Uma mesa e cadeira modestas, papéis espalhados, microfones e um pequeno vaso de flores. Giscard d'Estaing diz "adeus", levanta-se e sai do quadro. Por alguns segundos a câmara fica a mostrar aquele cenário desolador e vazio.

Aumont começa o seu livro Le Cinéma et la mise en scéne citando este exemplo porque, para este autor, temos aqui uma dupla encenação: "em primeiro lugar, a encenação vulgar da comunicação presidencial. De ele a nós, da "grande cabeça" (...) a todos os seus ouvintes." Uma encenação já convencional que obedece rigorosamente às regras deste tipo de evento. Em segundo lugar, temos a visão pouco usual do fora-de-campo, como uma espécie de bastidores por onde pode desaparecer a silhueta elegante do presidente francês - e à qual se junta e se opõe a encenação invulgar do operador de imagem sindicalista ou distraído, a permanência, contra qualquer expectativa, do quadro, do campo, do cenário, mesmo quando o ator já terminou a sua representação. ${ }^{1}$

O público televisivo não está habituado ao vazio em cena, à permanência do cenário sem que este exerça uma função muito específica. No caso acima exposto, Aumont questiona se, de fato, houve intencionalidade da parte do expresidente em criar, com o vazio da cena, uma metáfora visual da sua retirada da política, ou se foi meramente uma distração, ou mesmo boicote, do operador de imagem. O que interessa aqui é a conclusão que ele nos traz: independentemente da sua intencionalidade, a ideia de

Mirian Tavares é professora da Faculdade de Ciências Humanas e Sociais e do Mestrado em Comunicação, Cultura e Artes do Departamento de Línguas, Comunicação e Artes da Universidade do Algarve.

1 Jacques Aumont, O Cinema e a Encenação, Lisboa, Texto\&Grafia, 2008, p. 10. 
encenação esteve presente em todo o ato. E esta ideia não é nova na política, já que todos os regimes, sejam eles ditatoriais ou democráticos, são encenações para legitimar um discurso de poder. $\mathrm{O}$ surgimento da televisão tornou mais visível o espetáculo que, em alguns momentos históricos, já fora levado aos ecrãs pelo cinema.

Toda encenação tem a ver com teatro e teatralidade, pois foi o teatro que "desde cedo definiu formas, práticas e noções que modelaram a nossa vida social e o seu imaginário." 2 A questão que surge é: como é que a televisão e o cinema adequam o princípio da cena teatra ao seu próprio meio? Eisenstein, ao falar da relação entre o cinema e o teatro dizia que, enquanto no teatro temos a mise en scéne, no cinema temos a mise en cadre. Este realizador, que também foi encenador, conhecia a fundo as duas formas artísticas e, desde cedo, reconheceu que era necessário estabelecer para o cinema, arte ainda muito jovem, uma série de categorias próprias para evitar que ele sucumbisse às outras artes e ficasse apenas como um subsidiário das mesmas.

\section{Da mise en scéne a mise en cadre}

As relações entre o teatro e o cinema não foram ainda devidamente exploradas, apesar de alguns autores se terem debruçado sobre a questão. Aumont e Michel Marie distinguem três modos principais de relação destas duas formas artísticas: o teatro filmado, a "aereação" da peça, - ou seja, o trazer da cena para o exterior - e ainda a assunção da teatralidade do texto, e da representação pelo realizador. Neste último caso, assume-se claramente que tanto uma quanto outra forma artística estão baseadas numa série de convenções que se alteram com o tempo, o que ocorre em todas as artes, mas que são perfeitamente distinguíveis, em determinados mo- mentos. Assumir a teatralidade no filme é negar a sua filiação ao realismo, ou seja, é assumir a impossibilidade de o cinema revelar, efetivamente, o real.

Falar sobre a questão da representação entre teatro e cinema implica, antes de tudo, dizer de que teatro e de que cinema se está a falar. Porque há muitos pontos de contacto entre os dois, inclusive no que diz respeito às convenções da representação, já que o cinema acaba por herdar do teatro uma série de modelos. Basta pensar no cinema mudo e no cinema produzido pelas vanguardas históricas: tanto num como no outro, o cinema e o teatro partilham concepções formais e de conteúdo. O certo é que, para o cinema se afirmar, enquanto sétima arte, teve de cometer um parricídio necessário e fundamental para seu desenvolvimento enquanto arte autônoma. Parricídio não só em relação ao teatro, mas também em relação às outras artes referidas por Ricciotto Canudo, no seu $M a$ nifesto das sete artes de 1911.

O parricídio é o princípio de toda nova arte. Há que separar águas, antes de voltar a misturá-las. Cedo o cinema aprendeu que não era no teatro - pelo menos não no teatro "oficial" - que iria encontrar inspiração e atores que se adequassem à sua incipiente linguagem, apesar de compartilhar, com o teatro, em determinada época e contexto artístico-cultural, relações palpáveis, como são os casos do teatro e cinema expressionistas e do teatro e cinema formalistas. Mas quando saímos do âmbito das vanguardas e vamos para o cinema do Modo de Representação Institucional (M.R.I.), como Noel Burch prefere chamar ao cinema clássico hollywoodiano, vemos que há, da parte deste, uma necessidade de se afirmar como algo de diferente do teatro, usando-o até para destacar esta diferença.

Antes de o cinema surgir, havia já um desejo mundano de transformar a vida em espetáculo, em entretenimento, em deleite para os

\footnotetext{
2 Op. cit., p. 12.
} 
olhos. E Paris, centro do mundo ocidental no século XIX, atraía todos os olhares. O Guia Casell de Paris, de 1884, sublinhava que na cidade havia sempre algo "para ser visto". Vanessa R. Shwartz, num ensaio sobre o espectador cinematográfico antes do cinema, diz que "a vida real era vivenciada como um show, mas, ao mesmo tempo, os shows tornavam-se cada vez mais parecidos com a vida". ${ }^{3}$ Assim, a vida convertida em espetáculo pelo cinema era a resposta perfeita a este desejo hedonista e burguês presente, diga-se de passagem, em toda a arte do fim-do-século.

\section{O pintor da vida moderna}

O cinema é filho da cultura burguesa, com tendência realista-naturalista, e nasce como uma arte que incorpora a questão da tecnologia, da produção e da distribuição massivas. É, portanto, filho dos grandes centros urbanos que começam a espalhar-se pelo velho e pelo novo mundo. O fim do século XIX é marcado pela derrocada final de uma cultura ligada ao Ancien Régime. Era preciso encontrar respostas para o novo homem que surgia, para as cidades que se reconfiguravam, para um gosto volátil e efêmero que marcava o ritmo da produção em massa de objetos diversos, para o novo homem antevisto por Edgar Allan Poe no seu conto O Homem da Multidão e, mais tarde, dissecado por Baudelaire, em seu ensaio O Pintor da Vida Moderna.

Na passagem do século XIX para o século XX, a literatura e o teatro eram discursos hegemônicos. Se alguém queria mergulhar na narrativa e no drama, dirigia-se a um ou a outro. O cinema foi, paulatinamente, ocupando o lugar deste discurso. Talvez por ser a partida, mais adequado à nova realidade, ao novo homem, ao novo século. $\mathrm{O}$ que em nada prejudicou, nem a literatura, nem o teatro, que puderam, finalmente, libertar-se e seguir caminhos diversos e mais experimentais, ao longo do século XX. Mas se não prejudicou as velhas artes, sem dúvida, acabou por limitar, em muitos momentos, o discurso do próprio cinema. A nova arte se viu atada ao gosto do público que, por aqueles anos, passava a ser tratado por "massa".

$\mathrm{O}$ cinema industrial, feito para o grande público, conforme Burch, busca um modo de representação que quer ocultar a representação. Quer ser visto como algo que apresenta a vida mesma e não algo que a representa. Usa o ecrã como uma janela e convida os espectadores a espreitar o que se passa, a participar, de alguma maneira, desta outra vida que se instala ali. O início do cinema, antes do cinematógrafo dos Irmãos Lumière, está profundamente ligado à pulsão escopofílica. Afinal, o quinetoscópio de Edson incitava as pessoas a olharem imagens por um buraco, semelhante ao buraco de uma fechadura, e a gozar voyeuristicamente imagens feitas à medida para este prazer solitário.

Ao contrário do teatro que, enquanto arte do espetáculo, é arte pública e para o público, o cinema nasce como um ato solitário, um prazer não compartilhado. $\mathrm{O}$ espectador do cinema começa como um voyeur e, mesmo quando as imagens saltam para fora do quinetoscópio, a pulsão permanece. Ver cinema é espreitar a vida alheia. E é isto que o cinema do M.R.I. procura incentivar. E para isto usa o teatro, dentro dos filmes, como o espaço da representação. Uma peça, dentro de um filme, tem, antes de tudo, a função de demarcar uma zona entre a apresentação do mundo, feita pelo cinema, e a representação do mundo promovida pelo teatro.

3 Vanessa R. Shwartz, "O espectador cinematográfico antes do aparato do cinema: o gosto do público pela realidade na Paris fim-de-século", in L. Charney e Shwartz V. R., O Cinema e a invenção da vida moderna, São Paulo, Cosac e Naify, 2001. 


\section{Entre o público e o privado}

No teatro, a presença do corpo físico do ator dificulta objetificá-lo, espreitá-lo sem temer que ele nos olhe de volta. O cinema é composto de signos/sombras, já objetificáveis por essência. Arlindo Machado tece considerações sobre o pré-cinema e o voyeurismo, apresentando a permanência do modelo do quinetoscópio no cinematógrafo. O filme de voyeurismo aparece como uma espécie de gênero em 1900, com As seen through a telescope, de Smith. Vários outros exemplos se seguirão, até que o cinema encontre a sua gramática, e adquira um lastro cultural que a princípio não tinha.

Barthes disse, em relação ao teatro, que este é uma prática que supõe um "lugar calculado" de onde se observam as coisas, pois para haver representação é preciso o olhar do sujeito. Este lugar calculado mudou, ao longo do século XX, no que diz respeito ao teatro. Em torno de 1530, com o surgimento do palco italiano, é criado um fosso entre o real, a plateia, e a ficção, o palco. Esta sensação de distância entre a representação e o real é acentuada pelo teatro do Ancien Régime, duramente criticado por Diderot. O cinema, que aparece já sob a égide da cultura burguesa, arrasta consigo a tendência para o realismo, presente em diversos aspectos da arte do século XIX. Enquanto no cinema a tendência para o realismo acaba por se conjugar com um modelo de visionamento decalcado no palco italiano, o teatro abandona, gradualmente, o modelo condenado por Diderot, o da declamação, em busca de um gesto particular e de novas maneiras de representação, onde a distância entre a plateia e o palco pode mesmo deixar de existir.

O cinema herda do teatro o lugar calculado do sujeito que observa, lugar este tão bem evocado no filme de Alfred Hitchcock, Janela Indiscreta, onde um fotógrafo que sofre um aci- dente se vê obrigado a permanecer em casa, sem poder mover-se. Durante o período de convalescença, ele descobre um hobby que o distrai: observar os vizinhos através da objetiva da sua câmara. Do prédio em frente, vê apenas aquilo que as janelas revelam. O espaço "entre" estálhe vedado. E é neste espaço fora do seu campo de visão que acontece, supostamente, um assassinato. Como um espectador de cinema, a sua participação, a princípio, é passiva. Apenas observa e tenta adivinhar o que está oculto pelo espaço off. O olho da sua câmara pode aproximar as cenas que se desenrolam do outro lado do pátio, mas não conseguem perfurar as paredes e ver o que está para além do quadro da janela. Está limitado ao enquadramento e preso à sua cadeira, o seu lugar calculado.

Temos aqui exposto o paradoxo da imagem do cinema: de um lado ela dá-nos a sensação de que quase tocamos a realidade que nos circunda, mas somos limitados pelos enquadramentos e só temos permissão para ver o que se passa dentro do espaço in. Tornamo-nos voyeurs, voluntária ou involuntariamente. $\mathrm{E}$ como voyeurs, o que espreitamos são fragmentos do real. Ou assim o cinema nos quer fazer crer: não há representação, mas apresentação. Para se perceber com esta ilusão, ou mentira, é construída, recuemos um pouco, até ao nascimento da linguagem cinematográfica.

\section{A montagem ou a arte de iludir o olhar}

$\mathrm{O}$ cinema aprendeu, muito cedo, a mentir. E a chave da construção desta ilusão da realidade que ele vende, está na montagem. Eis a definição de Marcel Martin, que afirma: "a montagem é a organização dos planos de um filme em

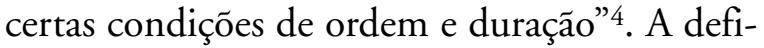
nição aparece praticamente em todos os manuais de montagem. É, por um lado, excessiva-

4 Marcel Martin apud J. Aumont et alii, A estética do filme. Campinas, Papirus, 1995, p. 54-5. 
mente generalista. Por outro lado, não deixa de corresponder à ideia básica do processo, que pode ser entendido como algo que atua sobre um objeto, e que possui algumas modalidades. "O objeto sobre o qual a montagem se exerce são os planos de um filme (ou seja, para explicitar ainda mais: a montagem consiste em manipular planos com o intuito de constituir um outro objeto, o filme); as modalidades de ação da montagem são duas: ela organiza a sucessão das unidades de montagem que são os planos; e estabelece sua duração." 5

A ideia de montagem, conforme Vicente Sánchez-Biosca, está presente em toda a arte do século XX. ${ }^{6}$ Se pensarmos, por exemplo, na collage do cubismo, ou mesmo em alguns métodos de construção do próprio texto surrealista, perceberemos que trabalhar a partir da fragmentos, recolocando-os numa nova relação de espaço e significaçōes, marca profundamente a arte das vanguardas. Talvez a atração que elas sentiram pelo cinema estivesse profundamente ligada a uma possibilidade que é intrínseca a este tipo de arte. Mas talvez possamos recuar um pouco mais, e encontrar os princípios da montagem cinematográfica nos romances do séc. XIX, principalmente na obra de Charles Dickens.

Num ensaio intitulado "Dickens, Griffith y el filme de hoy" sobre o cinema de Griffith e a importância deste na história do cinema, principalmente na do cinema soviético de então. Os filmes de Griffith, apesar de profundamente reacionários enquanto discurso, foram revolucionários enquanto forma. Para aqueles que, como Eisenstein, estavam interessados em compreender e criar uma verdadeira linguagem cinematográfica, o contato com aquele cinema serviu-lhes de lição. Uma lição que logo foi ultrapassada e, de certa maneira, rejeitada. A vanguarda soviética não cabia num tipo de filme que será o modelo básico do cinema clássico hollywoodiano.

Para Eisenstein, a importância de Griffith advém do fato deste ter aprofundado as questões da linguagem cinematográfica, elevando o cinema a um outro patamar: os filmes deixavam de ser apenas entretenimento e convertiam-se em uma forma artística $\mathrm{O}$ próprio Griffith não se considerava um inventor ${ }^{8}$, mas alguém que soube ler as obras de Dickens e perceber o potencial dramático das suas narrativas.

$\mathrm{O}$ realizador russo perguntava-se porque não outro escritor qualquer, já que o recurso da ação paralela não estava presente só na obra de Dickens, mas de muitos romancistas do período. O que este autor possuía, segundo Eisenstein, era a capacidade de criar um universo extraordinariamente plástico, onde as personagens são visíveis, mais que legíveis, fazendo parte de uma tipologia que facilmente salta para o ecrã. Para Stefan Zweig, Dickens nunca traçava visões vagas das personagens, dava aos leitores um retrato preciso, cheio de pequenos detalhes que tornavam as suas visóes tangíveis: uma mancha num vestido, um gesto recorrente, as mãos úmidas e frias de Uriah Heep que causava, nos leitores, repugnância. A psicologia das personagens, conforme Zweig, é construída pelo visível, pela capacidade de observação que Dickens possuía do mundo à sua volta. Griffith, e o cinema americano, retiram de Dickens um conceito de montagem, não só no sentido técnico

\footnotetext{
Ibidem.

Cf. Vicente Sánchez-Biosca, El montaje cinematográfico. Barcelona, Paidós, 1996, pp. 15-22.

S. Eisenstein, Teoria y tecnica cinematograficas, $4^{a}$ ed., Madrid, Ediciones Rialp, 1989, pp. 249-308.

8 Eisenstein, op. cit., p. 259, reproduz um texto publicado no The Times, de Londres, em 26 de abril de 1922, onde o autor, A. B. Walkley comenta: "Según él mismo admite, Griffith es más un precursor que un inventor. Esto significa que ha abierto nuevos caminos en el País del Cine, bajo la dirección de ideas que le han sido inspiradas por otros."
} 
de organização dos planos numa determinada ordem, mas no sentido mais amplo de construção de uma nova realidade a partir de fragmentos do real.

Se Griffith acreditava que o cinema seria capaz de abrir uma janela para o mundo, Sergei Eisenstein afirmava que o cinema era uma possibilidade de se abrir uma janela dentro do palco, de agilizar a cena e expandir o palco até limites nunca antes explorados. E foi com este intuito que dirigiu o seu primeiro filme, feito para integrar a encenação de uma peça de Ostrovsky, Até o mais sábio se deixa enganar. Eisenstein provocou um diálogo entre cinema e teatro, usando o primeiro para dar a sensação de simultaneidade em algumas cenas, para pontuar e acentuar outras situações e para reforçar a ideia de uma montagem que excedia a própria ideia de montagem convencional: montase não apenas quando se junta fragmentos, mas quando se confrontam ideias. E este é o princípio de uma série de conceitos fundamentais que mais tarde ele irá explorar, tanto no campo da teoria, quanto na sua práxis, enquanto cineasta.

Ao contrário de Eisenstein que defendia a montagem como o gesto fundamental para a criação de uma linguagem cinematográfica, André Bazin afirmava que a montagem só poderia ser utilizada dentro de limites muito rigorosos para não correr o risco de atentar contra a ontologia da "fábula cinematográfica." . Assim sendo, rejeitava a proposta de utilização da montagem das vanguardas artísticas, sobretudo do Formalismo Russo. Para este autor, o cine- ma sustenta-se na possibilidade de revelar, como numa epifania, o mundo. De uma maneira ou de outra, defendendo ou atacando a montagem como princípio, os pontos de vista de Bazin e de Eisenstein acabam por chegar ao mesmo porto: o cinema deveria ser uma janela capaz de ampliar a nossa visão. Do mundo ou do palco.

\section{0 cinema como linguagem}

No célebre ensaio "Ontologia da imagem fotográfica”, Bazin revela a sua posição em relação às imagens fotográfica e cinematográfica. Neste ensaio, é possível detectarmos as nuances do seu pensamento, que parece em alguns momentos contradizer-se. Católico de formação, mergulhado na fenomenologia e no existencialismo que povoavam o pensamento francês da época, Bazin constrói uma interessante teoria sobre o cinema: se, por um lado, a imagem fotográfica, para ele, possui um caráter ontológico, pois a realidade acaba por colar-se à sua reprodução, por outro lado ele reconhece que o cinema, fotografia em movimento, é uma linguagem.

Assim, o cinema, ao mesmo tempo que revela o mundo, possui uma linguagem que o constitui e o distancia do real. O cinema não é só revelação, mas também construção, manipulação. Mas a manipulação existe para que se tenha uma ilusão de continuidade espacial, muito próxima daquela calcada na realidade ${ }^{10}$. O cinema do M.R.I. escamoteia a montagem, mostrando os eventos como que dotados de uma

9 André Bazin apud Alejandro Montiel, MONTIEL, Alejandro. Teorias del cine - un balancehistórico. Barcelona, Montesinos, 1992, p. 62.

10 "O sistema de Bazin baseia-se num postulado ideológico de base, articulado em duas teses complementares, que seria possível formular da seguinte maneira:

- na realidade, no mundo real, nenhum evento é dotado de um sentido totalmente determinado a priori (é o que Bazin designa pela idéia de uma "ambiguidade imanente ao real");

- a vocação "ontológica" do cinema é reproduzir o real respeitando ao máximo essa característica essencial: o cinema deve portanto produzir representaçōes dotadas da mesma "ambiguidade" - ou se esforçar para isso." (J. Aumont et alii, op. cit., p. 72). 
continuidade espaço-temporal que de fato eles não possuem. Bazin dá-nos uma definição deste tipo de cinema em seu livro sobre Orson Welles:

Qualquer que seja o filme, seu objetivo é darnos a ilusão de assistir a eventos reais que se desenvolvem diante de nós como na realidade cotidiana. Essa ilusão esconde, porém, uma fraude essencial, pois a realidade existe em um espaço contínuo, e a tela apresenta-nos de fato uma sucessão de pequenos fragmentos chamados "planos", cuja escolha, cuja ordem e cuja duração constituem precisamente o que se chama "decupagem" de um filme. Se tentarmos, por um esforço de atenção voluntária, perceber as rupturas impostas pela câmera ao desenrolar contínuo do acontecimento representado e compreender bem por que eles nos são naturalmente insensíveis, vemos que os toleramos porque deixam subsistir em nós, de algum modo, a impressão de uma realidade contínua e homogênea. ${ }^{11}$

No início do séc. XX, um dos primeiros teóricos do cinema, Hugo Munsterberg, relacionava o modo de funcionamento dos filmes com o modo de funcionamento da mente humana. A forma de construção da imagem cinematográfica é, em quase tudo, semelhante à da maneira como a nossa mente percebe o mundo, utilizando os mesmos mecanismos, como a atenção, a memória e a imaginação. Para este psicólogo, o filme realiza-se na mente do espectador e não apenas no ecrã. Ele vai ainda traçar pontos de dessemelhança entre o cinema e o teatro, ao demonstrar, através da sua teoria, que a capacidade de o cinema envolver os espectadores numa ilusão de realidade, não estava presente no teatro.

Apesar de o cinema ter absorvido o modelo da cena italiana como modelo de exibição, o lugar do espectador aqui não é o mesmo do lugar do espectador do teatro. Não é o mesmo porque o cinema, através da manipulação do ponto de vista, dos movimentos da câmara, do uso dos recursos que possui para a construção da imagem, leva o seu espectador a sair do lugar, a penetrar no ecrã, a saltar da cadeira para dentro daquela realidade outra, criada pelo realizador. Por isso Munsterberg dizia que o cinema acontece dentro de quem o visiona e não no ecrã. O que possibilita ao cinema ampliar, ainda mais, a ilusão de realidade. Um filme como Otelo, de Welles, que foi realizado ao longo de três anos, em lugares diversos, é visto pelo espectador como um continuum espaço-temporal. Através da manipulação das imagens, feita no processo de montagem do filme, o espectador vê, no ecrã, apenas uma cidade: Veneza.

\section{O Processo do Rei}

Orson Welles, através da montagem, faz com que o espectador não perceba que a Veneza do ecrã não existe. É apenas um compósito de fragmentos de locações diversas. E esta é uma das diferenças marcantes entre o teatro e o cinema: a capacidade que o segundo possui de encenar o espaço, de torná-lo único ou multifacetado conforme a proposta do realizador. O que vemos existe apenas no ecrã, não tem uma realidade palpável como a de um cenário teatral. Em 1990 o diretor português João Mário Grilo realiza o seu terceiro longa-metragem, $O$ Processo do Rei. Neste filme utiliza um procedimento semelhante ao de Welles, por motivos diversos, mas com um resultado similar. Reconstrói, através de fragmentos de lugares reais, o lugar onde a trama do seu filme se desenrola.

O filme é baseado num documento histórico, de 12 páginas, que fala sobre o processo ao qual foi submetido o Rei Afonso VI, o vitorioso. O processo, no filme, não é mera narra-

11 André Bazin apud J. Aumont et alii, op. cit. p. 74. 
tiva, mas é apresentado em toda a sua força imagética e presencial. Não há ficcionalização intencional, mesmo que a história seja também ela, uma narrativa sujeita à pena de quem conta (há dois registros deste processo, feitos na altura, um contra e outro a favor). Como apresentar um processo e ao mesmo tempo não tomar partido? Como reconstruir o momento histórico sem recriar cenários? O realizador tentou reconstituir o Paço da Ribeira, espaço onde se desenrola a história, recorrendo a um recurso profundamente cinematográfico: a montagem. Correu pelo país e, de fragmentos de espaço, montou um todo convincente.

Se Aumont afirma que toda a política é encenação e para tal utiliza o exemplo da dupla encenação televisiva de Giscard d'Estaing, João Mário, através do seu filme, revela-nos vários níveis de encenação: a política, que comanda o espetáculo; a visual que remete-nos para o tempo/espaço onde a narrativa se vai desenrolar e a mise en scéne do filme onde os atores e o cenário fazem-nos ter consciência, o tempo inteiro, de que estamos a ver um espetáculo e não um fragmento do real.

O filme nos faz saltar diretamente dentro da história, não por uma elaborada criação narrativa mas pela elaborada criação visual (escudada pela fotografia de Eduardo Serra). Os ambientes fazem com que os espectadores sejam reenviados para o século XVII,e assistam a um espetáculo que ali vai se desenrolar. Ao reconstituir o Paço da Ribeira com fragmentos do real, João Mário tece um espaço cênico que nos envolve a todos, espectadores e personagens, numa atmosfera única. A mise en scéne também é trabalhada ao pormenor: os atores têm a aguda consciência da representação e cumprem o duplo papel de participar de um processo histórico que foi, como tal, uma farsa urdida nos bastidores para levar D. Pedro II ao poder, e de estar num filme, onde nele são atores.

Cada plano é desenvolvido como um tableaux vivant, apesar de não o ser. Há referências explícitas, na iluminação e composição de alguns enquadramentos, ao Barroco, mas não há reproduçôes, nas imagens do filme, de quadros deste período. Há a lentidão do filme, que nos convida a entrar num outro tempo, e assim, o realizador, recupera o cinema primitivo: na imobilidade da câmara, na teatralidade do seu princípio e nos enquadramentos do cenário que apesar de calcado no Real, parece construído. O próprio Barroco é aqui recuperado/retratado na sua essência: um grande palco onde se desenrolava a História.

No filme a presença do Barroco não é mero pano de fundo, mas um elemento narrativo e presentificador da História. Por exemplo, o Barroco português nutriu um verdadeiro amor pela simulação, de tal forma que grandes pinturas portuguesas do período, mais do que criaçôes originais, eram, na verdade, composições de um novo espaço cênico baseado em imagens alheias, tomadas de empréstimo de outras gravuras e quadros. No filme vemos uma reprodução do quadro o Cordeiro Místico de Josefa de Óbidos, obra emblemática da arte portuguesa. A escolha do quadro não é apenas para dar mais credibilidade ao cenário e para situarnos na época do acontecimento histórico. Este quadro é um modelo típico do barroco português, criado a partir de outro quadro, O Cordeiro, do pintor espanhol Zurbarán. Ao mostrar o quadro de Josefa de Óbidos, João Mário revela-nos parte do seu próprio procedimento: recria, através de citaçóes e referências, as paisagens de Chardin, os interiores de Vermeer, o requintado mundanismo dos retratos de Ticiano, a Vênus no espelho e os anões de Veláquez, toques de Rembrandt... Sem recriar os quadros recria, através de fragmentos, um tempo e um espaço onde a imagem teve importância fundamental. Afonso VI foi o rei, que, segundo o diretor, teve toda a sua vida comandada pelo espelho. E João Mário consegue, através da encenação proposta e da realização do filme, refletir (na dupla acepção da palavra), sobre as relações da História com o teatro, do teatro com o cinema e deste com todas as artes que o rodeiam. 


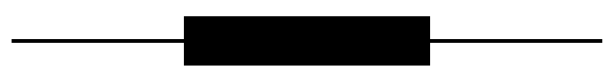

\section{Referências bibliográficas}

AGEL, Henri, Estética do cinema. São Paulo, Cultrix, 1982.

ANDREW, Dudley. As Principais teorias do cinema. Rio de Janeiro, Jorge Zahar, 1989.

ARMES, Roy. The ambiguous image. Indianapolis, Indiana University Press, 1976.

AUMONT, Jacques. O Cinema e a Encenação. Lisboa, Texto\&Grafia, 2008.

AUMONT, Jacques et alii. A estética do filme. Campinas, Papirus, 1995.

. Estética del Cine .2a ed., Barcelona, Paidós, 1996.

AUMONT, Jacques e MARIE, Michel. Dicionário teórico e crítico de cinema. Campinas, Papirus, 2003.

BAUDELAIRE, Charles. Sobre a modernidade. Rio de Janeiro, Paz e Terra, 1996.

BAZIN, André. O cinema da crueldade. São Paulo, Martins Fontes, 1989.

O cinema. São Paulo, Brasiliense, 1991.

BORAU, José Luis. La pintura en el cine, el cine en la pintura, Madrid, Ocho y Medio, 2003.

BURCH, Noel. Praxis del cine. Madrid, Fundamentos, 1983.

CHARNEY, L. e SCHWARTZ, V. R. O Cinema e a invenção da vida moderna. São Paulo, Cosac e Naify, 2001.

EISENSTEIN, Sergei. "Montagem de atraçōes" in Ismail Xavier (org.), A experiência do cinema, Rio de Janeiro, Graal, 1983, pp. 187- 198.

A forma do filme. Rio de Janeiro, Jorge Zahar, 1990.

. Teoria y tecnica cinematograficas. 4a ed., Madrid, Ediciones Rialp, 1989.

HUESO, Ángel Luis. El cine y el siglo XX.Barcelona, Ariel, 1998.

MACHADO, Arlindo. Pré-cinemas e pós-cinemas. Campinas, Papirus, 1997.

MONTIEL, Alejandro. Teorias del cine - un balance histórico. Barcelona, Montesinos, 1992.

MURCIA, Claude et Menegaldo, Gilles. L'expression du sentiment au cinéma. Poitiers, La Licorne, 1996.

SÁNCHEZ-BIOSCA, Vicente. El montaje cinematográfico. Barcelona, Paidós, 1996.

XAVIER, Ismail. O discurso cinematográfico: a opacidade e a transparência. $2^{\text {a }}$ ed., Rio de Janeiro, Paz e Terra, 1984.

(org.). A experiência do cinema. Rio de Janeiro, Graal, 1983. 
RESUMO: Este texto discute as relações entre o cinema e o teatro a partir do conceito de mise en scéne. O que aproxima, e distancia, estas duas formas artísticas? De que maneira o cinema, ao longo da sua história, construiu a sua própria mise en scéne recorrendo, sobretudo, à montagem? Para aprofundar as questões levantadas pelo texto, irei analisar o filme O Processo do Rei (1990), de João Mário Grilo. Baseado no processo contra D. Afonso VI, o realizador conseguiu ser fiel ao tempo histórico, séc. XVII, mas também profundamente contemporâneo, explorando aspectos eternos e cíclicos da própria História. O cinema, neste filme, funciona como um palco onde a História revela a encenação que os livros de História costumam ocultar.

PALAVRAS-CHAVE: encenação; cinema e teatro; cinema e história; João Mário Grilo. 